\title{
INTERDISCIPLINARY APPROACH IN THE TREATMENT OF IMPACTED CANINES - review and a case report
}

\author{
Svetlana Yordanova ${ }^{1}$, Hristina Lalabonova ${ }^{2}$, Miroslava Yordanova ${ }^{1}$ \\ ${ }^{1}$ Department of Orthodontics, Faculty of Dental Medicine, \\ ${ }^{2}$ Oral surgery department, Faculty of Dental Medicine, \\ Medical University - Plovdiv, Bulgaria
}

\begin{abstract}
The successful management of severely impacted maxillary canine requires close cooperation of an orthodontist, an oral surgeon, a radiologist a periodontist and a prosthodontist.

The present report reviews the literature on diagnosis on treatment and management of impacted maxillary canines and presents the interdisciplinary and individual approach to a 14 year-old patient with severely impacted upper right canine.

Extraction of permanent impacted maxillary canine is not a routine method, but it is sometimes a good and inevitable choice. A beautiful smile and functional occlusion can be achieved in the absence of the canine and by the rest of the available teeth.
\end{abstract}

Key words: impacted maxillary canine, extraction, management of impacted canine.

\section{INTRODUCTION}

Effective management of impacted canines is still a challenge in dental medicine.

Without the expert evaluation and the close collaboration of several specialists - an orthodontist, an oral surgeon, a radiologist a periodontist and a prosthodontist, the diagnosis and the management of severe cases can often be compromised.

The aim of the present report is to review the literature on diagnosis on treatment and management of impacted maxillary canines and to present the interdisciplinary and individual approach to a 14 year-old patient with severely impacted upper right canine.

The diagnosis of impacted maxillary canine has to be based on both clinical examinations - disease history and status (clinical examination and palpation) and paraclinical examination - biometrical analysis and radiographic investigations $(1,2)$.

According to Bishara (3) there are a number of clinical signs that indicate the impaction of the upper canine: delayed eruption of the permanent canine, overretained deciduous canine (after the age of 14-15 years), absence of a normal labial canine bulge along the alveolar ridge; presence of a bulge on the palatal side of the alveolus or distal tipping of the lateral incisor.

Radiological diagnosing methods for impacted canines include: periapical films, occlusal radiography after Simpson, orthopantomography (OPG) and teleroentgenography (frontal and lateral) $(1,3)$.

The introduction of CT scan and Cone Beam 3-D scan facilitate localization of impacted tooth and enhance the choice of treatment plan. A number of authors $(4,5)$ recommend computed tomography (CT) as it gives more detailed information on the canine in relation to the position of the incisors, the presence of root resorption and its severity, compared to conventional radiography.

Using polytomographic technique Ericson and Kurol (6) found that the number of teeth that were diagnosed as resorbed almost doubled due to ectopically located canine.

Shuller and Freisfeld (7) found during high resolution CT of 35 impacted teeth that only 5 of the patients did not manifest signs of damage to the remaining teeth.

Conventional CT is a modern diagnostic method, but the radiation dose is too high. Low radiation compared to CT scans (8), high resolution slices (to $0.09 \mathrm{~mm}$ ) and the precise measurements (8) are features that make cone-beam computed tomography (CBCT) a preferred means of dental image diagnosing and of orthodontics in particular (9).

$27 \%$ of teeth that were planned to be left, uncovered, or extracted, with the $2 \mathrm{D}$ radiographs had different treatment plan when the judges viewed the 3D images (10). Of course this highly informative technology requires competent radiologists to aid the orthodontist in diagnosing the X-ray image of the impacted canine.

After a thorough diagnosis an individual approach to each patient is required. Many authors investigate various treatment modalities $(3,11,12,13)$.

1. Autotransplantation of the canine $(14,15,16,17)$ is an alternative method of treatment that gives this important tooth the chance fulfill its aesthetic and functional role. The success of such an approach depends on the patient's age, the form and the status of the impacted canine, as well as the form and status of adjacent teeth and the 
presence of enough space.

2. Surgical uncovering and orthodontic alignment to the line of occlusion is the most desirable and recommended approach (1). Age, position of the tooth, retention severity, est. are factors that influence the choice of the above approach. According to those factors there are two alternatives for orthodontist:

-surgical exposure and allowing for natural eruption on the palate $(3,18)$;

-surgical exposure with the placement of an auxiliary attachment and subsequently applied orthodontic force to extrude the tooth (3).

3. Extraction of the impacted tooth is another method of treatment. It requires consequential actions for the replacement of the tooth: displacement of distal teeth, putting implants (19) or prosthetic construction (20,21).

Extraction indications of an impacted canine according to Bishara (3) are:1. ankylosis and impossible tooth transplantation; 2. severe root dilaceration; 3 . severe retention (lodged between lateral and incisor roots, horizontal placement), in which surgical uncovering and orthodontic extrusion will hold risks; 4. first premolar is in the position of the canine, there is good occlusion and well aligned teeth; 5. pathological changes around the tooth (cysts etc.) and the patient is unwilling to be orthodontically treated.

Frank Ch. (12) thinks, that the tooth extraction depends on the patient's age, dental status of adjacent teeth (their form, resorption, parodontal, endodontic and operative status), dental status of the impacted tooth itself, occlusal relationship and arch length $(13,22,23)$.

According to Bedoia M. (2) when the canine has any restrictions regarding its localization or anatomy, its extraction is the only choice.

Complications related to the extraction of palatally impacted canines are numerous (12): huge bone defects, damage of adjacent teeth (luxation, compromised parodontium, root fractures), involvement of maxillary sinus, neuropathies. That is why a similar kind of intervention is usually a last clinical approach to ectopic upper canines. Carried out properly and in close collaboration with a radiologist, a surgeon and an orthodontist, it leads to satisfactory results.

The case that we present illustrates a complex approach to the treatment of a severely impacted maxillary right canine which is in accordance with the radiological findings, opportunities for surgical intervention and last but not least, the patient's choice. The patient P. Tz., 14 years old was referred to treatment because of complaints due to improperly aligned teeth. The thorough clinical examination revealed permanent dentition with a missing tooth 13 , vestibular depression between teeth 12 and 14 and a palatal buldge upon alveolar palpation to the right (fig. 1)
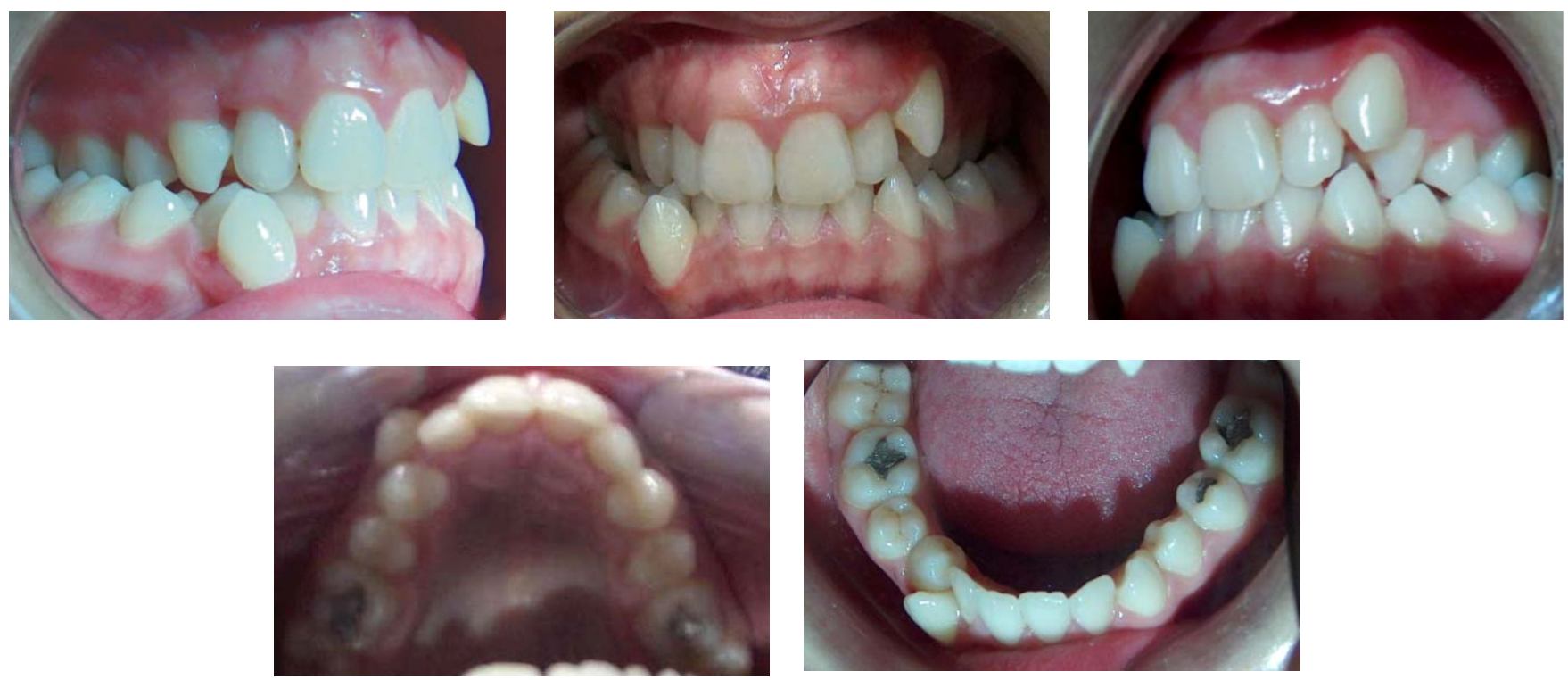

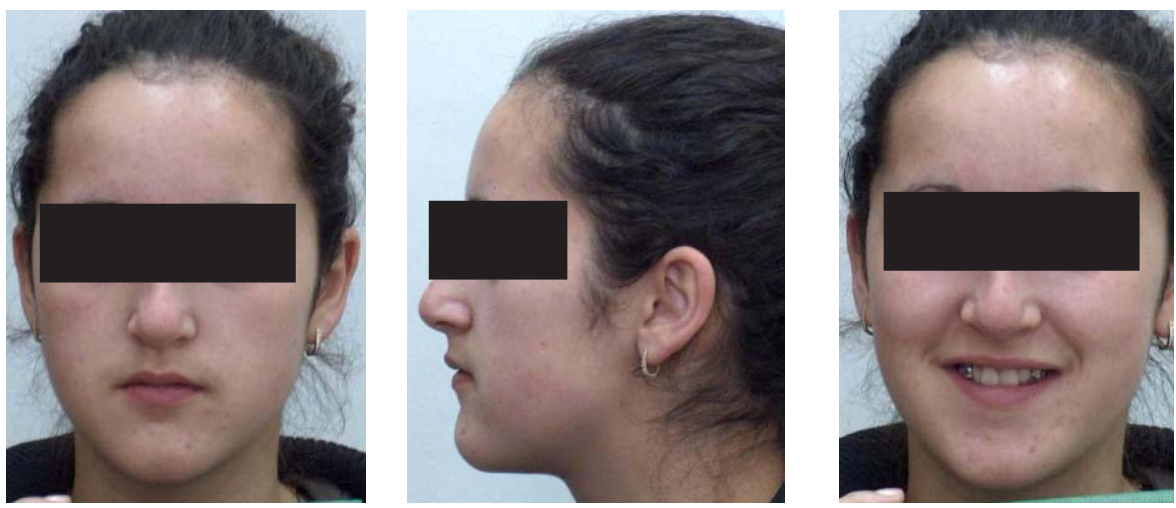

Fig. 1. Intra-oral and extra-oral photos of the patient P.Tz., 14 years old with impacted upper right canine (before treatment)

The biometrical analysis of cast models showed premolar and molar maxillary constriction over $10 \mathrm{~mm}$, dental midline shift to the right, presence of contact between teeth 12 and 14, vestibular position of teeth 23 and 43, bilateral cross-bite, unilateral left molar class II dental relationship.
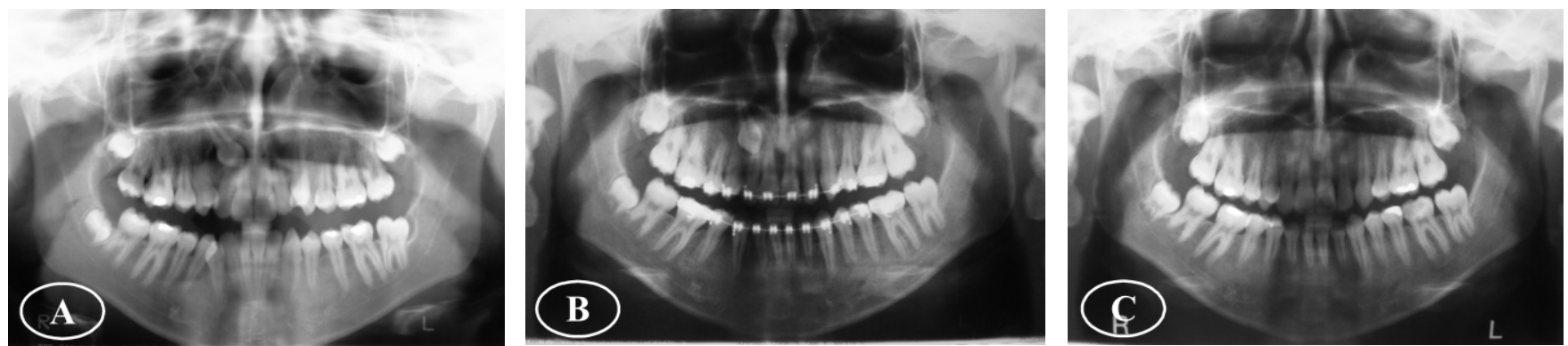

Fig. 2. Orthopantomography of the patient P.Tz., 14 years old: A-before treatment, B-after maxillary expansion, Cafter treatment

Occlusal radiography (Fig. 3) showed a vestibularlingual position of the tooth proximal to the palatal midline.
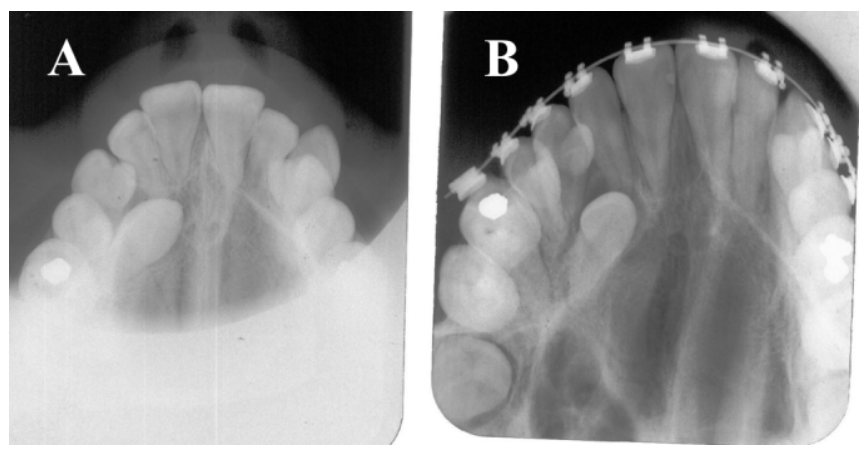

Fig. 3. Occlusal radiography after Simpson of the patient P.Tz., 14 years old: A-before treatment, B- after maxillary expansion. 
Cephalometric assessment determined III skeletal class (Witts $=-2 \mathrm{Mm}$ ) and a hyperdivergent type of growth $(<\mathrm{Mp} / \mathrm{SN}=43 \mathrm{ヶ},<\mathrm{Mp} / \mathrm{Sp}=3$ ъ 4$)$. It revealed as well the high retention of the upper canine - its crown was situated at the level of the apices of teeth 11 and 12, its root passes over the border of the palate and it is proximal to the maxillary sinus.

After a consultation with a maxillo-facial surgeon the severe retention of 13 was confirmed in terms of difficult surgical access and the risks related to its uncovering and extraction. The patient was informed on the partial or full failure of the treatment and after her informed consent the following treatment plan was adopted:

\section{Orthodontic phase}

- Maxillary expansion to normal size. It was carried out by the rapid palatal expander (Hyrax) for 20 days with a morning and an evening activation.

- Leveling and aligning of both dental arches. It was performed by multibracket fixed appliance MBT $0.22^{\circ}$.

2. Surgical phase

- Extraction of teeth 24 and 44 to ensure space for teeth 23 and 43.

3. Orthodontic phase

Leveling and aligning of teeth 23 and 43 .

4. Control radiological diagnosis after 14 months with CBCT scan (Fig. 4).

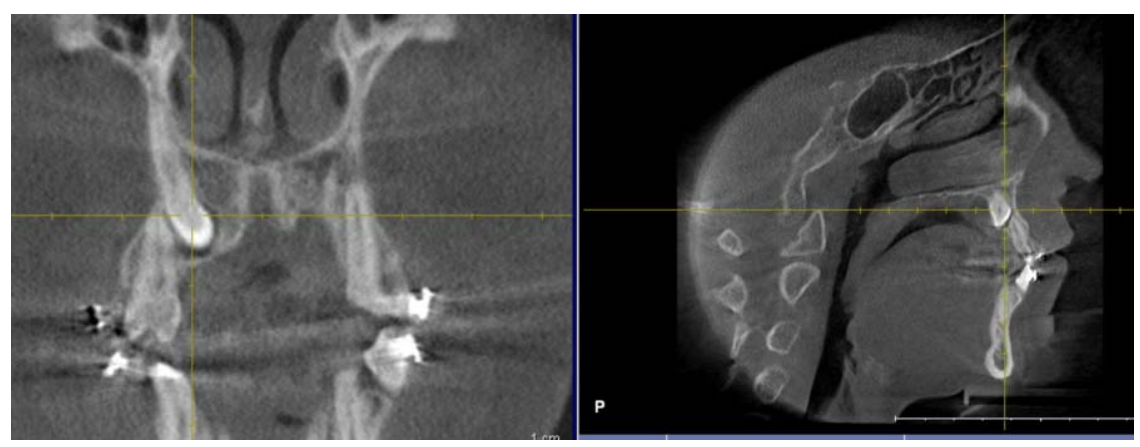

Fig. 4. CBCT of the patient P.T., 14 years old, showing high position of the tooth 13 in proximity to the teeth 12 and 14 .

\section{Surgical phase}

- Extraction of tooth 13 after 20 months.

6. Orthodontic phase

- Closing of spaces.

- Finishing phase - adjustment of arches done by vertical elastics.

- Retention - lower fixed retainer from canine to canine and an upper removable appliance.

Active treatment time was 38 months (Fig. 5).
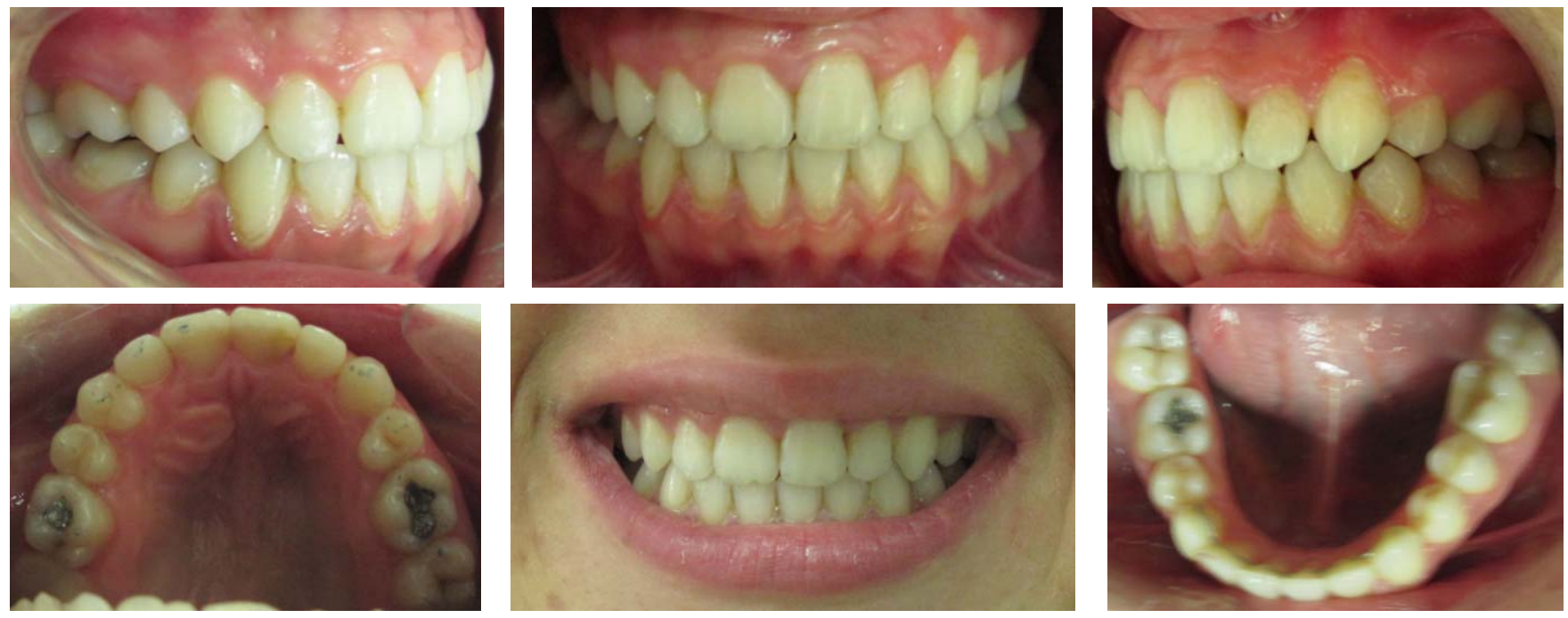

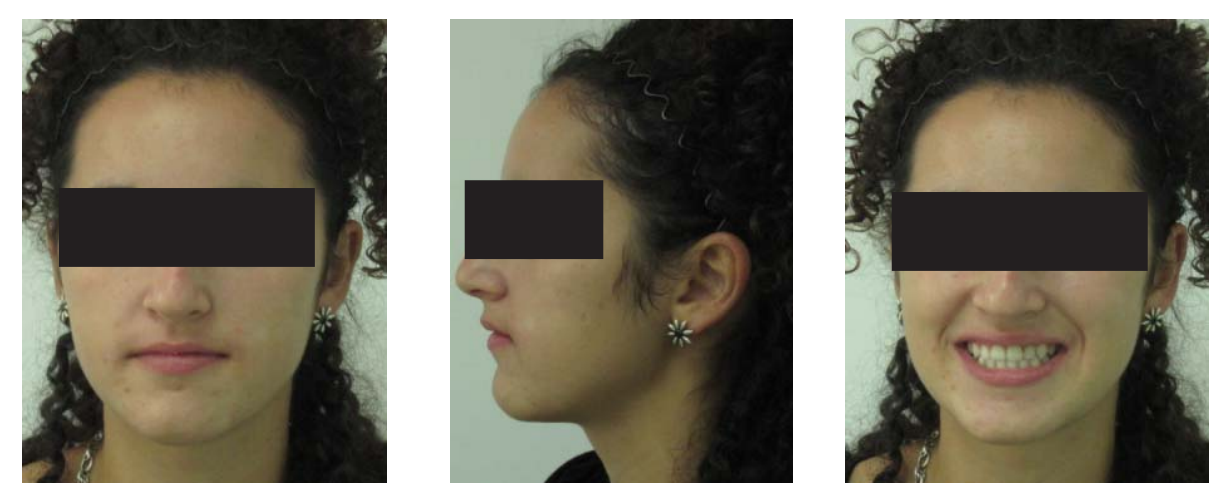

Fig. 5. Fig 1 Intra-oral and extra-oral photos of the patient P.T., 14 years old with impacted upper right canine (after treatment).

\section{DISCUSSION}

The clinical case herewith reported presents a more rarely preferred treatment approach for ectopically displaced upper canines - namely extraction of a palatally impacted tooth.

The initially chosen complex treatment plan for this specific patient included surgical exposure and orthodontic leveling of the impacted tooth 13 to the occlusal line (3). After maxillary expansion the control OPG revealed (Fig. 2B) that the impacted canine moved to upright position, but it still was too high in the apical third of the incisors. Moreover, for its alignment in to the dental arch, tooth 14 had to be extracted as it had totally occupied the place of tooth 13 .

In severely impacted upper canines there is always the risk that they are likely to be extruded into the palate due to probable ankylosis, devitalisation, major surgical trauma, etc. That is why it is recommendable to postpone molar extraction until successful movement of the canine has started. Otherwise a probable and reliable substitute of the canine may be lost (3). In the reported case, however, in order to try to move 13 we had to first extract 14 . The risks and the possible outcome success degree were explained to the patient. To be able to come to a precise decision we recommended and carried out 3D diagnosis by CBCT scan because of its proven advantages $(8,9)$. Radiological findings showed too high position of the tooth in proximity to the maxillary sinus and to the roots of 14 and 12. After a consultation with a surgeon the patient was offered a change of therapeutic plan regarding the impacted tooth - extraction instead of uncovering and orthodontic extrusion. At this stage after the surgeon's opinion and due to difficulties in surgical access and probable undesired complications at the time of the manipulation (e.g. accidental sinus involvement, root trauma to adjacent teeth) the operation postponed and rescheduled to be carried out in about 6 months. The surgical finding at the time of extraction confirmed that the chosen approach was the right one although it prolonged the total treatment time. The impacted canine had moved to a much proper for the surgical uncovering position and its extraction underwent without traumas. The final control OPG revealed a very good healing process with no presence of a huge bone defect (Fig. 2C). The final treatment resulted in stable functional occlusion and with class II molar relationship to the left.

\section{CONCLUSION}

Extraction of permanent impacted maxillary canine is not a routine method, but it is sometimes a good and inevitable choice. A beautiful smile and functional occlusion can be achieved in the absence of the canine and by the rest of the available teeth.

Due to a complex interdisciplinary approach and the new diagnosing methods it is possible to choose the optimal and individually oriented option for the treatment of severe forms of impacted maxillary canines. Thus unnecessary complications in orthodontic treatment can be avoided and the surgical intervention risks can be reduced. 


\section{REFERENCES:}

1. Bishara SE. A presrective on the management of impacted maxillary canines. Orthodontic review 2007; vol 9 (2):6-22.

2. Bedoya M., Park JH. A review of the diagnosis and management of impacted maxillary canines. J Am Dent Assoc. 2009 Dec;140(12):1485-1493. [PubMed]

3. Bishara SE. Clinical management of impacted maxillary canines. Semin Orthod 1998 Jun;4(2):87-98. [PubMed]

4. Elefteriadis JN, Athanaasiou AE. Evaluation of impacted canines by means of compujerized tomography. Int J Adult Orthod Orthognath Surg. 1996; 11(3):257264. [PubMed]

5. Schmuth GP, Freisfel M, Koster O, Schuller H. The application of computerized tomography (CT) in cases of impacted maxillary canines. Eur J Orthod 1992 Aug;14(4):296-301. [PubMed]

6. Ericson S, Kurol J. Radiographic examination of ectopically erupting maxillary canines. Am J Orthod Dentofacial Orthop 1987 Jun;91(6):483-492. doi: 10.1016/0889-5406(87)90005-9 CrossRef] [PubMed]

7. Schuller H, Freisfeld M. Damage to the remaining teeth from displaced upper canines. Fortschritte auf dem Gebiete der Rontgenstrahlen und der Neuen Bildgebenden Verfahren 1992 Aug;157(2):107-110. (Article in German) [DOI: 10.1055/s-20081032980 CrossRef] [PubMed]

8. Scarfe WC, Farman AG, Sukovich P. Clinical applications of cone beam computed tomography in dental practice. J Can Dent Assoc 2006 Feb;72(1):75-80. [PubMed]

9. Yovchev D. CBCT in dental imaging diagnostic. Roentgenologia radiologica 2009; volXLVIII: 17-21.

10. Haney E, Gansky SA, Lee JS, Johnson E, Maki K, Miller AJ, Huang JC. Comparative analysis of traditional radiographs and cone beam computed tomography volumetric images in the diagnosis and treatment planning of maxillary impacted canines. Am J Orthod Dentofacial Orthop 2010 May;137(5):590597. doi:10.1016/j.ajodo.2008.06.035 CrossRef] [PubMed]

11. Andreeva L, Angelova B. Problems in the treatment of palatal impacted maxillary canine. Orthodontic review 2005; vol. 7(1): 9-18.

12. Frank Ch. Treatment options for impacted teeth. J Am Dent Assoc. 2007; 131: 623-632. [PubMed]

13. Kokich VG, Mathew DS. Surgical and orthodontic management of impacted teeth. Dent Clin North Am 1993; 37:181204. [PubMed]

14. Show BM, Schneider SS, Zeyer J. Surgical management of ankylosed impacted maxillary canines. J Am Dent Assoc. 1981 Apr;102(4):497-500. [PubMed]

15. Sayne S, Lennartsson B. Thilander B. Transalveolar transplantation of maxillary canines. An alternative to orthodontic treatment in adult patients. Am J Orthod Dentofacial Orthop. 1986 Aug;90(2):149-57. [doi:10.1016/08895406(86)90047-8 CrossRef] [PubMed]

16. Arikan F, Nizam N, Sonmez S. 5year longitudinal study of survival rate and periodontal parameter changes at sites of maxillary canine autotransplantation. J Periodontal 2008; 79(4):595-602. [doi:10.1902/jop.2008.070409 CrossRef] [PubMed]
17. Negi K, Rangila Ram, Autotransplantation -an alternative management of compromised impacted maxillary canine. The Orthod Cyberjournal orthocj.com/2011/01/.

18. Schmidt AD, Kokich VG. Periodontal response to early uncovering, autonomous eruption and orthodontic alignment of palatally impacted maxillary canines. Am J Orthod Dentofacial Orthop 2007 Apr;131(4):449-455 doi:10.1016/ j.ajodo.2006.04.028 CrossRef] [PubMed]

19. Garcia B, Boronat A, Larrazabal C, Penarrocha M, Penarrocha M. Immediate implants after the removal of impacted maxillary canines. A clinical series of 9 patients. Int J Oral Maxillofac Implants. 2009 Mar-Apr;24(2):348-52. [PubMed]

20. Magheri P, Cambi S, Grandini R. Restorative alternatives for the treatment of impacted canines: surgical prosthetic considerations. Pract Proced Aesthet Dent 2002 Oct;14(8):659-664, quiz 666. [PubMed]

21. Penarrocha M, Penarrocha M, Garsia-Mira B, Larrasabal C. Extraction of impacted maxillary canines with simultaneous implant placement. J Oral Maxillofac Surg. 2007 Nov;65(11):23362339. [doi:10.1016/j.joms.2005.07.024 CrossRef] [PubMed]

22. Di Salvo NA. Evaluation of unerupted teeth orthodontic viewpoint. J Am Dent Assoc. 1971 Apr;82(4):829-35. [PubMed]

23. Wise RJ. Periodontal diagnosis and management of impacted maxillary cuspid. Int J Periodontics Restorative Dent 1981; 1(2):56-73. [PubMed]

\author{
Address for correspondence: \\ Dr. Svetlana Yordanova \\ Department of Orthodontics, Faculty of Dentistry, Medical University, Plovdiv \\ 2, Hristo Botev Str., 4000 Plovdiv, Bulgaria \\ Mobile: 00359878147640 , \\ E-mail: svetlaj@gmail.com
}

